\title{
A POSIÇÃo Do SUJEITO NA FALA E SEUS EFEITOS: UMA REFLEXÃO SOBRE OS QUATRO DISCURSOS
}

\author{
Denise Macedo Ziliotto ${ }^{1}$ \\ Instituto de Psicologia - USP
}

\begin{abstract}
Ensaiar aproximações entre a psicanálise e a psicologia social na discussão sobre a temática do sujeito no trabalho é a proposta deste texto. A formulação dos quatro discursos, proposta por Lacan, pode contribuir com novos paradigmas para o estudo desta questão, pois introduz e contextualiza os depoimentos existentes na cena social acerca do trabalhar. Este recorte, advindo da linguagem, justifica-se pelo traço diferencial que marca a civilização e os sujeitos, singularizando-os. Desta forma, pretende-se propor uma escuta diferente a este que fala de seu sofrimento ao trabalhar.

Descritores: Discurso. Capitalismo. Trabalho. Lacan, Jacques, 19011981.
\end{abstract}

Dresumo que seja cabível introduzir o contexto em que esta produção textual insere-se. Minha pesquisa de doutoramento em Psicologia Social tem o trabalho como categoria central. Insatisfeita com as abordagens tradicionais que o qualificam como objeto central da vida humana, ou assujeitam o indivíduo à estrutura econômica-social, busco outras vertentes para resgatar uma postura mais implicada e responsável do sujeito.

Neste sentido, a contribuição de Lacan é valiosa e, infelizmente, pouco compreendida entre os psicólogos sociais e/ou do trabalho. Pretendo exa-

1 Doutoranda do Programa de Pós-Graduação em Psicologia Social e do Trabalho, Instituto de Psicologia - USP. Endereço eletrônico: dmziliotto@ hotmail.com 


\section{Denise Macedo Ziliotto}

tamente esta aproximação. Tomar a teoria lacaniana para lançar luzes sobre este tema tem, como conseqüência, beber em fontes que foram referências para este autor, como Hegel e Marx. Trata-se, portanto, de um ganho importante: a questão se amplia na medida que resiste ao determinismo, ao reducionismo de outras leituras.

Persigo a idéia de que há uma montagem, na cultura contemporânea, entre consumir e trabalhar, enquanto construtores de uma subjetividade particular que, sem dúvida, persiste, porque confere algum grau de gozo ao sujeito. É a possibilidade de evocar o sujeito que se beneficia da afânise do discurso capitalista que norteia minha reflexão.

Sendo a palavra e as possibilidades advindas de nomear o mundo (o mundo das coisas, o mundo interior, o mundo das sensações...) o que caracteriza os humanos, pode-se pensar que não são desprezíveis as implicações contidas nesta potencialidade. Desde já considera-se que as particularidades de usufruto da língua revelam que o sujeito age sobre a sua falação, atribui nuances, significados, sentidos, ultrapassando o arbitrado. Neste sentido, há uma operação que se faz presente: o dizer está para além da linguagem, está do lado do falante.

A formulação lacaniana dos Quatro Discursos faz-se particularmente interessante para construir reflexões acerca desta questão, que se encontra implicada (como posteriormente avançaremos) com o sujeito no trabalho. Ao referir sobre um sujeito que fala, há sobretudo que se considerar a quem fala e, sobretudo, de que lugar fala. Algo se opera, diferentemente, dependendo destes contingentes, adquirindo um movimento especial entre o falante e seu interlocutor. Introduzir esta dimensão é incluir a fala do sujeito sobre o seu trabalho como algo que se reflete, imediatamente, sobre o seu trabalhar, sobre as relações que estabelece neste campo. Trata-se de, novamente, incluir e responsabilizar o sujeito e que também é no trabalho.

Nesta construção de Lacan, explicitada no Seminário - O Avesso da Psicanálise (Lacan, 1969-1970/1992), há uma investida importante sobre a cultura e a cena social, marca do estilo deste autor. Contrariamente ao que se pode (erroneamente) atribuir às formulações psicanalíticas - considerando-as 
como um campo homogêneo e hermético -, o pecado pelo enclausuramento clínico, a noção lacaniana abarca a dimensão da contemporaneidade. Ao situar os discursos, reconhece a pluralidade e busca explicitar lugares sociais, a saber: discurso universitário, discurso da histérica, discurso do mestre, discurso do analista e discurso capitalista.

Darmon (1994, p. 112) especifica o fundamento ontológico desses discursos, descrevendo que os sujeitos são determinados pelo deslocamento do significante (entendido como o que representa o sujeito para um outro significante) em seus atos e em seu destino, independentemente de seu sexo ou do que comumente se chama de sua psicologia. Têm-se desta forma a defesa de um sujeito que é pela linguagem, pelos significados que atribui e expressa na relação com o mundo: “(...) toda determinação de sujeito, portanto de pensamento, depende do discurso". (Lacan, 1969-1970/1992, p. 144). Situando o sujeito como aquele que emana da linguagem e não do pensamento, como propõe a filosofia desde o cogito cartesiano, ocasiona uma outra dimensão: "No efeito da linguagem, não se trata de nenhum ente. Trata-se apenas de um ser falante. No ponto de partida não estamos no nível do ente, mas no nível do ser" (p. 144).

Uma diferença está marcada aí: invertendo o cogito de Descartes, Lacan afirma que o sujeito está onde não pensa. "Só em função dessa primeira posição do Sou é que se pode escrever o Penso" (Lacan, 1969-1970/1992, p. 146). Acrescenta, propondo a inversão:

\footnotetext{
Mas também aqui há um erro de pontuação, que há muito exprimi assim - o ergo, que nada mais é do que o ego na jogada, tem que ser posto do lado do cogito. $\mathrm{O}$ Penso logo: 'Sou', eis o que dá seu verdadeiro alcance à fórmula. A causa, o ergo, é pensamento. Aí está o ponto de partida a ser empreendido do efeito daquilo que está em questão na ordem mais simples, cujo efeito de linguagem se exerce no nível do surgimento do traço unário. (p. 146)
}

Desta forma, Lacan resgata a primazia da subjetividade sobre a racionalidade, ao evocar a categoria do traço unário, pois é pela linguagem que o pensamento se opera. Sendo assim, não há ser racional por excelência, já que a linguagem se institui pelo que manca, pela tentativa insistente de cons- 
trução subjetiva. É na cadeia do discurso, ou seja, na série de associações que realiza ao falar, que o sujeito se produz. Através da linguagem há a tentativa de dar conta do impossível, da impotência que marca o humano; falar é gozar, diz Lacan, referindo o quanto há de tamponamento da falta no uso da linguagem.

Nesta referida busca, a teoria lacaniana descreve quatro modalidades por meio das quais se tenta fazer algo com este impossível, com o saber, em última instância. E é sobre a posição que os sujeitos tomam em relação a este saber que estes discursos são articulados.

No discurso do mestre, que poderia aproximar-se de uma fala do ego, há a idéia de que quem fala sabe sobre o que fala. Há o recalcamento da falta, é o discurso da possibilidade do saber. Encontra-se, por exemplo, na fala dos políticos. O discurso do analista provoca exatamente o desvelamento do recalcado, isto é, desinstitui a pretendida e estável formulação. Provoca a queda do saber suposto, para que o sujeito possa produzir outros saberes ou mesmo relativize os que possui. Visa à produção do inconsciente, através da associação-livre, ou seja, o "fala-ser".

O discurso universitário prega que há um conhecimento erudito ao qual o aluno deve se assujeitar; há um saber sobre o objeto (o aluno como objeto), em como este deve ser. O saber é da ordem de um grande Outro, o que provoca a alienação do sujeito. Buscar um mestre que possa dominar o saber é o intuito da histérica que, por sua vez, recalca a falta e provoca a fala no corpo. Contudo, o efeito deste discurso é provocar o saber, pois ele desafia a autoridade, a teoria estabelecida, propondo insistentemente a dúvida sobre o saber do Outro.

Estes discursos, como descreve Darmon (1994), têm seus termos constitutivos - significante mestre $\left(\mathrm{S}_{1}\right)$, saber $\left(\mathrm{S}_{2}\right), \$$ (sujeito barrado) $a$ (objeto a - causa do desejo) - alocados em lugares que não permitem comutação, justamente expressos em matemas que transmitem a posição evidenciada em cada discurso. A saber: 
O Lugar de Onde o Sujeito Fala e seus Efeitos- uma Reflexão Sobre os Quatro...

\begin{tabular}{cc}
\hline $\begin{array}{c}\text { Discurso do Mestre } \\
\frac{S_{1}}{\$} \rightarrow \frac{S_{2}}{a}\end{array}$ & Discurso Universitário \\
\hline Discurso da Histérica & $\frac{S_{2}}{S_{1}}$ \\
\hline$\frac{\$}{a} \rightarrow \frac{S_{1}}{S_{2}}$ & Discurso Analista \\
\hline
\end{tabular}

Figura 1: Os quatro discursos.

Na conferência de Milão, em 1972, Lacan menciona um quinto discurso, citado rapidamente em seu seminário, que particularmente interessa à temática deste estudo: o discurso capitalista. Neste, contrariamente aos outros, os termos não são isolados; cada um alimenta no outro uma reação em cadeia, cuja tendência é o arrebatamento (Darmon, 1994, p. 223).

\begin{tabular}{|cc|ccc|}
\hline$\$$ & $S 2$ & agente & $\rightarrow$ & trabalho \\
$\downarrow$ & $\downarrow$ & $\uparrow$ & & $\downarrow$ \\
$S 2$ & $a$ & verdade & $\leftarrow$ & produção \\
\hline
\end{tabular}

Figura 2: O quinto discurso.

Aqui, o lugar da verdade não é mais protegido, ele é alimentado pelos quatro vértices. No discurso do mestre, o escravo era o saber, já "nesse discurso, a denúncia da verdade não faz senão reforçar o processo; Lacan cita como exemplo o próprio papel de Marx" (Darmon, 1994, p. 225). O saber não circula, mas é assegurado pelos elementos, com uma cumplicidade que será explicitada a seguir. "A pretensa libertação do escravo teve, como sem- 
pre, outros correlatos. Ela é progressiva à custa de um despojamento" (Lacan, 1969-1970/1992, p. 140).

Precisa-se, inicialmente, retomar o discurso do mestre. Ele é escutado com certo deleite, como denuncia Lacan, mantendo certa dominação. "Isto é provado pelo fato de que, explorados ou não, os trabalhadores trabalhem" (p. 160).

Jamais se honrou tanto o trabalho, desde que a humanidade existe. E mesmo, está fora de cogitação que não se trabalhe. Isto é um sucesso, então, do que chamo de discurso de mestre. Para isso foi necessário que ele ultrapassasse certos limites. (...). Falo dessa mutação capital, também ela, que confere ao discurso do mestre seu estilo capitalista. (p. 160)

A formulação proposta por Lacan é engendrada a partir do discurso do mestre. Isto porque o mestre é aquele que detém o saber, que sabe o que deve ser feito. O oferecimento desta certeza produz seus efeitos, já que é sedutor pensar na existência de uma verdade sobre as coisas do mundo.

No discurso capitalista, o proletário é despossuído do saber, o que "justifica tanto o empreendimento como o sucesso da revolução", como afirma Lacan (1969-1970/1992, p. 30), alicerçando-se em Hegel (precisamente na Dialética Senhor - Escravo explicitada na Fenomenologia do Espírito) e na leitura de $O$ Capital de Marx, suas postulações. Retomam-se essas referências a posteriori, de modo a explorar essas contribuições como esclarecedoras da temática aqui apresentada.

Seu saber, a exploração capitalista efetivamente o frustra, tornando-o inútil. Mas o que lhe é devolvido, em uma espécie de subversão, é outra coisa - um saber de senhor. E é por isso que ele não fez mais do que trocar de senhor (p. 30).

Quando se refere à troca de senhor, não se trata mais do senhor do escravo, mas de um outro senhor, o capital, e, sobretudo, o saber do senhor sobre seu trabalho:

Eis o que constitui a verdadeira estrutura do discurso do senhor. O escravo sabe mu itas coisas, mas o que sabe muito mais ainda é o que o senhor quer, mesmo que este não o saiba, o que é o caso mais comum, pois sem isto ele não seria um senhor. O es- 
O Lugar de Onde o Sujeito Fala e seus Efeitos- uma Reflexão Sobre os Quatro...

cravo o sabe, e é isto sua função de escravo. É também por isso que a coisa funciona, porque, de qualquer maneira, funcionou durante muito tempo. (p. 30)

Contudo, há um giro nesse saber, no discurso capitalista. O tudo-saber passou para o lugar do senhor. Há uma nova tirania do saber (da verdade):

O sinal da verdade está agora em outro lugar. Ele deve ser produzido pelos que substituem o antigo escravo, isto é, pelos que são eles próprios produtos, como se diz, consumíveis tanto quanto os outros. Sociedade de consumo, dizem por aí. Material humano, como se enunciou um tempo - sob os aplausos de alguns que ali viram ternura. (p. 30)

A denúncia de uma sociedade que sucumbe à verdade das coisas, à verdade de quem as produz, consumida por esta sedução, é o alerta lacaniano. $\mathrm{O}$ amor à verdade, ilusão denunciada por Lacan, faz o papel de negar a impossibilidade do saber-todo. Afinal, a que saber o sujeito imagina ter conquistado acesso? E que saber realmente almeja?

\begin{abstract}
A nova ênfase no saber do explorado me parece estar profundamente motivada na estrutura . A questão é saber se isso não é algo totalmente sonhado. Em um mundo onde emergiu, de maneira que existe de fato, sendo uma presença no mundo, não o pensamento da ciência, mas a ciência de algum modo objetivada (...) que por enquanto ocupam o mesmo espaço que nós no mundo em que essa emergência teve lugar, será que o savoir-fare, no nível do manual, pode ainda ter peso suficiente para ser um fator subversivo? (Lacan, 1969-1970/1992, pp. 140-141)
\end{abstract}

Neste sentido, pode-se pensar o quanto a superioridade da ciência, nos nossos dias, é reificada continuamente. E o quanto a impossibilidade do sujeito em seu trabalho, na estrutura capitalista, é reafirmada. Trata-se de uma lógica que descompromete o sujeito. Remete a instâncias macro, o que é construído nos discursos - cotidianos - dos sujeitos.

Ziliotto, D. M. (2004). The subject's position in speech and its efects: A reflection on the four discourses. Psicologia USP, 15(1/2), 215-223. 


\title{
Denise Macedo Ziliotto
}

\begin{abstract}
This text attempts to bring psychoanalisis and social psychology together into the discussion on the matter of the subject at work. The four discourses formulation proposed by Lacan can contribute to the study of such matter with new paradigms, since it introduces and contextualizes the existing reports about work in the social scene. Such approach originated from language is justified by the differential trace that marks the civilization and the subjects, sigularizing them. It is intended, then, to propose a different analytical listening to the one who talks about one's suffering at work.
\end{abstract}

Index terms: Discourse. Capitalism. Work. Lacan, Jacques, 1901-1981.

Ziliotto, D. M. (2004). Le lieu d'où parle le sujet et ses effets: une réflexion sur les quatre discours. Psicologia USP, 15(1/2), 215-223.

Résumé: Essayer des approches entre la psychanalyse et la psychologie sociale dans la discussion sur la thématique du sujet au travail; voici la proposition de ce texte. La formulation des quatre discours, proposée par Lacan, peut apporter des nouveaux paradigmes pour l'étude de cette question, puisque elle introduit et contextualise les témoignages qui existent dans la scène sociale à propos de l'acte de travailler. Cette vision, issue du langage, se justifie par le trait différentiel qui marque la civilisation et les sujets et les singularise. De cette façon, on prétend proposer une écoute différente à celui qui parle de sa souffrance au travail.

Mots-clés: Discours. Capitalism. Travail. Lacan, Jacques, 1901-1981.

\section{Referências}

Darmon, M. (1994). Ensaios sobre a topologia lacaniana. Porto Alegre, RS: Artes Médicas.

Lacan, J. (1992). O Seminário. Livro 17: O avesso da psicanálise. Rio de Janeiro: Jorge Zahar. (Trabalho original publicado em 1969-1970)

Nogueira, L. C. (2002). Aula ministrada no Instituto de Psicologia da Universidade de São Paulo. (Trabalho não publicado) 
O Lugar de Onde o Sujeito Fala e seus Efeitos- uma Reflexão Sobre os Quatro...

Voltolini, R. (2001). Aula ministrada no Instituto de Psicologia da Universidade de São Paulo. (Trabalho não publicado)

Recebido em 09.06.2004 Aceito em 06.08.2004 